\title{
УДК 624.131.1:528.7 \\ СХОДИМОСТЬ РЕЗУЛЬТАТОВ ДИСТАНЦИОННОГО МЕТОДА ДЕШИФРИРОВАНИЯ С ПОЛЕВЫМИ РАБОТАМИ НА ЛИНЕЙНОМ ОБЪЕКТЕ. НА ПРИМЕРЕ ОПОЛЗНЕВОГО УЧАСТКА
}

\author{
Баборыкин Максим Юрьевич, \\ mybaborykin@rnrtc.ru
}

000 «НК «Роснесрть»- НТЦ», Россия, 350000, г. Краснодар, ул. Красная, 54.

\begin{abstract}
Рассматривается технология воздушного лазерного сканирования, применяемая для изучения топограсрии, геоморфологии и картирования опасных геологических процессов с описанием, требуемым в нормативных документах, а также сопоставление данных дистанционного метода прогнозного определения зеркала скольжения с геофизическими и геологическими методами исследований.

Цель: проведение работ для получения положительной статистики применения метода дешифрирования материалов воздушного лазерного сканирования совмещенного с иифровой аэрофотосъёмкой для изучения оползней; сопоставление прогнозных данных зеркала скольжения с классическими геологическими и геофизическими исследованиями оползневого участка и, как следствие, выявление надежности применения метода дешифрирования материалов воздушного лазерного сканирования.

Объект: участок склона проектного проложения магистрального трубопровода. Предмет исследования - гравитационные геологические процессы, их форма, состояние и активность.

Методы: метод дешифрирования материалов воздушного лазерного сканирования с выделением оползней по прямым признакам. Так как лазерное сканирование местности позволяет получить массив точек лазерных отражений от поверхности грунта при наличии растительности, выделение оползней по прямым признакам позволяет установить их границы и текстурные особенности. Применялись традиционные методы исследований, геодезическая съёмка местности, бурение скважин, геофизические исследования и т. д.

Результаты. Сопоставление дистанционного метода и полевых изысканий показало достаточно высокую сходимость по выявлению оползней (границ тел и их внешнего облика). Определение предполагаемого зеркала скольжения оползня по его внешнему облику для дополевой оценки также показывает сходимость результатов достаточную для оценки при выборе конкурентных направлений. Мировой опыт, накопленный в области применения аэрометодов в съемках, показывает их исключительную эфффективность. Таким образом, метод эфффективен для принятия проектных решений перед полевыми исследованиями, а также исключает возможность недоизученности территории непосредственно перед началом полевых исследований.
\end{abstract}

\section{Ключевые слова:}

Рельефф, опасные геологические процессы, дешифрирование, изучение оползней, инженерно-геологическое картирование, воздушное лазерное сканирование, геофизические методы исследований, магистральный трубопровод.

\section{Введение}

Практически любое строительство начинается с изучения природных условий, влияющих и определяющих размещение проектируемых сооружений, а также их эксплуатацию. В зависимости от назначения проектируемого сооружения оценка его природной обстановки проводится по факторам, составляющим инженерно-геологические условия, которые определяют решение инженерной задачи. Одним из главных факторов инженерно-геологических условий является рельеф - то есть его морфометрические и морфографические данные в сочетании с его развитием [1].

Рельеф представляет собой результат сложного взаимодействия эндогенных и экзогенных сил и выполняет роль контактной поверхности между литосферой, с одной стороны, и атмосферой, гидросферой криосферой - с другой [1].

Эндогенные силы, проявляющиеся главным образом в форме тектонических движений, приводят к образованию наиболее крупных форм рельефа - гор, равнин, межгорных котловин и др.

Экзогенные проявления в процессах выветривания, денудации и аккумуляции приводят, с одной стороны, к более дробному расчленению форм рельефа, созда- ваемых тектоническими движениями, а с другой - к образованию новых, аккумулятивных форм рельефа.

На всех этапах инженерно-геологических исследований, начиная со съёмок мелкого и среднего масштаба и заканчивая изысканиями под конкретные инженерные объекты, большое внимание уделяется изучению геологических процессов, главным образом экзогенных и, в известной форме, эндогенных - землетрясений (точнее их проявлений). Экзогенные геологические процессы развиваются в результате сложного взаимодействия большого числа природных факторов. Важными факторами, определяющими возникновение и контролирующими развитие геологических процессов, являются рельеф, климат, геологическое строение территории, направление и интенсивность современных тектонических движений, степень сейсмической активности территории.

Дешифрирование материалов воздушного лазерного сканирования для изучения инженерно-геологических и гидрогеологических условий

Инженерно-геологические изыскания включают в себя дешифрирование аэрокосмических материалов и аэрофотоснимков [2]. Данные, полученные при про- 
ведении съёмки LiDAR, являются одним из видов аэро-материалов.

Согласно СП 11-105-97, ч. I, работы по проведению дешифрирования материалов аэросъемки предусматриваются при изучении и проведении оценки инженерно-геологических условий территорий, отведенных под проекты линейных сооружений с большой протяженностью и площадных объектов значительных по площади, а также, на объектах, на которых необходимо проводить изучение динамики изменения природной и природно-технической систем [3].

Под дешифрированием материалов воздушного лазерного сканирования (ВЛС) понимается получение информации о геологических условиях изучаемой территории путем их выявления и распознавания на цифровых моделях рельефа (ЦМР), построенного из массива точек лазерных отражений (ТЛО), класс «земля». Совмещение ЦМР с другими классами ТЛО (травяная растительность, кустарниковая растительность, древесная растительность и т. д.) и аэрофотоснимков в каналах RGB (R - красный, G - зелёный, В - синий) с ортотрансформацией дает полную модель местности для дистанционного обследования изучаемой территории. Также для повышения информативности модели могут быть включены космо-, спектрозональные, гиперспектральные аэрофотоснимки и данные аэрогеофизических методов [4].

Дешифрирование материалов ВЛС для изучения инженерно-геологических условий на участке исследования включало в себя [5]:

- сбор исходных данных (топографические карты, физико-географическое описание района) при необходимости;

- проведение съёмки LiDAR по треку сканирования с выбором высоты и скорости полета летательного аппарата для наилучшего сканирования;

- классификацию точек лазерных отражений, ортотрансформацию аэрофотоснимков, построение карт интенсивности отражений;

- построение ЦМР;

- проведение ортотрансформации цифровой аэрофотосъёмкой (ЦАФС);

- загрузку подготовленных ЦМР и ортофотоснимков в географическую информационную систему (ГИС);

- распознавание очертаний экзогенных геологических процессов, проявленных в рельефе, и линеаментов по типичным элементам, составляющим очертания геологических процессов и образованных геологических тел (оползни, конусы выноса, осыпи и т. д.), для построения контурных карт экзогенных геологических процессов [6];

- построение тематических карт (уклонов, градиентов уклонов, текстуры поверхности, выпуклости и вогнутости склонов и т. д.); совмещение полученных карт в ГИС с цифровой моделью рельефа для проведения дешифрирования материалов ВЛС для изучения экзогенных геологических процессов с определением качественных и количественных характеристик, линеаментов и геологических структур; проведение расчета вероятности появления склоновых процессов;

- создание векторных слоев и баз данных в ГИС;

- составление предварительных карт инженерногеологических условий, карты экзогенных геологических процессов, контурных карт экзогенных геологических процессов и линеаментов;

- присвоение класса (опасный геологический процесс) к выявленным экзогенным геологическим процессам по отношению к будущему сооружению [7-10].

Алгоритм проведения дешифрирования материалов ВЛС, представленный на рис. 1, позволяет получить качественные и количественные характеристики выявленных опасных геологических процессов, морфометрические характеристики рельефа, а также экзогенных геологических процессов и проявленных на поверхности земли эндогенных геологических процессов и геологических структур.

Определение качественных характеристик оползневого тела. Данный подход основан на определении физиономических характеристик, отображенных на ЦММ сопоставляемых с эталонными моделями оползней, которые обладают набором признаков, характерных для определенного типа оползня [11-29]. Изучается форма оползневого тела в рельефе, его элементы: бровка срыва, бровка главного уступа, бугры, западины, наличие струйчатой эрозии на теле оползня и т. п., а также их явное или неявное проявление в рельефе, наличие или отсутствие растительности.

Определение количественных характеристик оползневого тела. Получение метрических характеристик, размеров, определяется посредством инструментария ГИС, а прогнозное определение зеркала скольжения производится на 3D ЦМР по внешнему облику оползневого тела, по углу падения главного уступа, крутизне склона, подошве оползня и расположению оползневого тела в пространстве [11].

Исследуемый участок в геологическом отношении расположен в Кизилташской антиклинальной зоне (рис. 2).

Полный комплекс методов анализа показал:

Tun рельефа: низкогорный структурно-эрозионноденудационный.

Морфометрические характеристики: длина склона около 340 м (от вершины водораздела до подошвы). Средняя величина уклона участка изысканий составляет 13 град. Приводораздельный склон 9 град., уклон бровки срыва 20 град., уклон поверхности оползневого тела 11 град. (головная часть 12 град., язык 8 град.). Густая эрозионная сеть временных водотоков. Эрозионные врезы V-образные, что говорит об активной донной эрозии, превышающей аккумуляцию.

Характер эрозионных врезов и оползней по распространению и «геоморфологическому облику опасных геологических процессов (ОГП)» говорит о грунтах, сложенных мелкодисперсным материалом (суглинки, глины). Для унификации и обобщения пред- 
лагается понятие «геоморфологический образ опасных геологических прочессов - устойчивое сочетание морфометрических элементов и форм, типичных для того или иного опасного геологического прочесса» [3].

При дешифрировании материалов ВЛС (мезорельеф) выделены грязевулканические отложения, перекрытые делювием на водоразделе и приводораздельном склоне. Склоны в основном представлены гравитационными отложениями, деляпсием. В эрозионных врезах выделяются конусы выноса временных водотоков, представленных пролювиальными отложениями (мелкодисперсный материал). Речная долина в районе ирригационного канала и рисовых чеков представлена аквальными отложениями (аллювиально-лимническими).

Эндогенные геологические процессы представлены грязевулканической деятельностью в виде конуса неактивного древнего грязевого вулкана.

Выявленные экзогенные геологические процессы:

1. Криповое течение грунта по склонам. Выявляется микроступенчатость на ЦМР при изучении форм микрорельефа. Образование крипа связано с сезонным переувлажнением грунтов, прилегающих к дневной поверхности.

2. Оползневые процессы. Выделяются три типа оползней по механизму (классификация оползней по типам их механизма В.В. Кюнтцеля): а) вращения - образованы дугообразные цирки оползней, бровки срыва и главный уступ подверглись денудации, контура оползней на момент дистанционного обследования (2014 г.) ярко выражены в телах оползней, видны образования линейной эрозии временных водотоков, не имеющих пережа- тий, сдвижек осей стока или иных видимых изменений. Предварительно оползневые тела сложены дисперсными отложениями (по характеру бровки срыва), имеют длительную стабилизацию (рис. 3); б) вязкопластические - образованы дугообразные цирки оползней, бровки срыва ярко выражены, не сденудированы. Хорошо различимы особенности микрорельефа: остроугольные перегибы к главному уступу, наличие бугров и западин. Вывод: новое геологическое тело (оползень), недавно образованное в более древнем геологическом теле (оползне) - недавно сошедший. При проведении дешифрирования материалов ВЛС по косвенным признакам выявлено близкое расположение грунтовых вод к дневной поверхности в подошве склона (присутствие в почвенном покрове растений, относящихся к группе влаголюбивых: камыш), происходит циклическая разгрузка, которая является одним из важных факторов образования оползней (рис. 3); в) плоского смещения - образован дугообразный цирк отрыва, бровка отрыва подверглась денудации, блок оползневого тела перемещен до подножья склона, отчетливо видна переработка нижней части смещенного блока (рис. 3).

Донная эрозия временного водотока. Площадь водосбора для образования достаточно глубоких эрозионных врезов небольшая. Возможно близкое расположение грунтовых вод к дневной поверхности, происходит циклическая разгрузка, позволяющая сформировать эрозионные врезы и спровоцировать появления осовов грунта (мелких оползней) и оползней по бортам вреза.

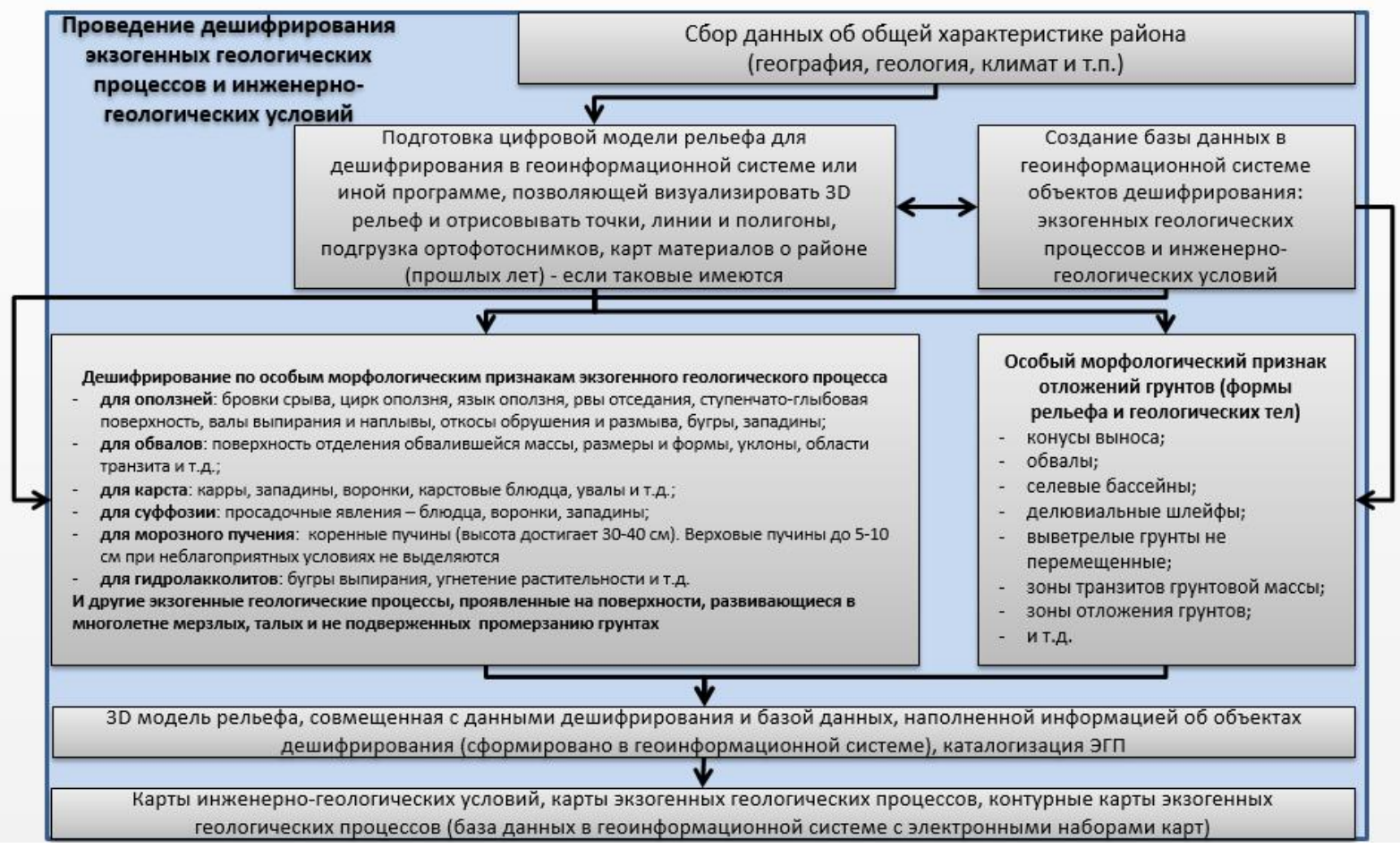

Pис. 1. Схема алгоритма проведения дешифрирования материалов ВЛС (Патент № 2655955)

Fig. 1. Scheme of the interpretation algorithm (Patent No. 2655955 (RU)) 


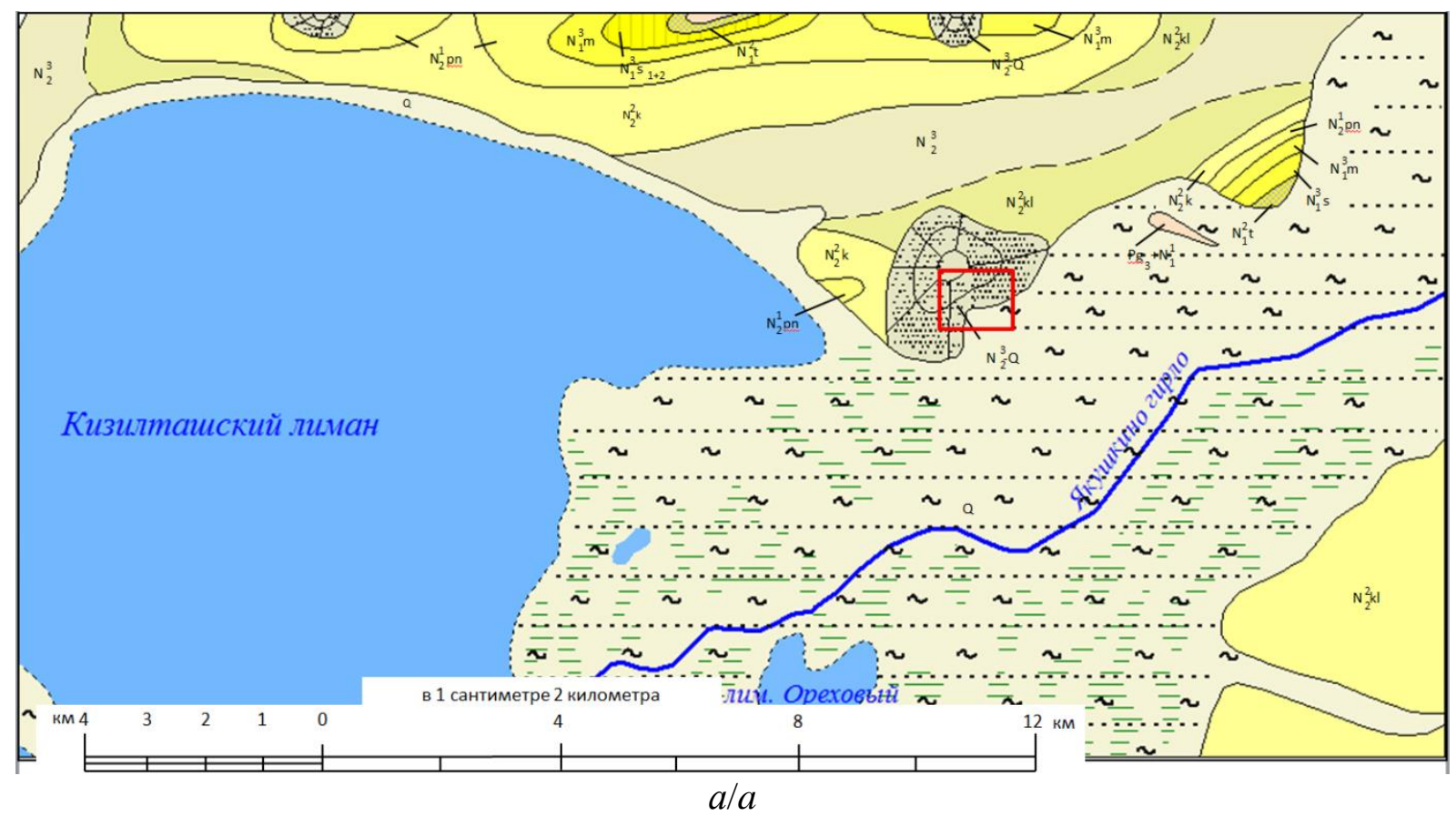

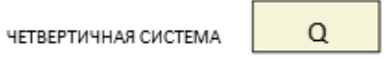

Современные отложения. Галечники, пески, суглинки, илы

HEOГEHOBAЯ И ЧЕТВЕРТИЧНАЯ СИСТЕМЫ

\section{$\mathrm{N}_{2}^{3} \mathrm{Q}$}

Верхний плиоцен -четвертичная система. Сопочная брекчия

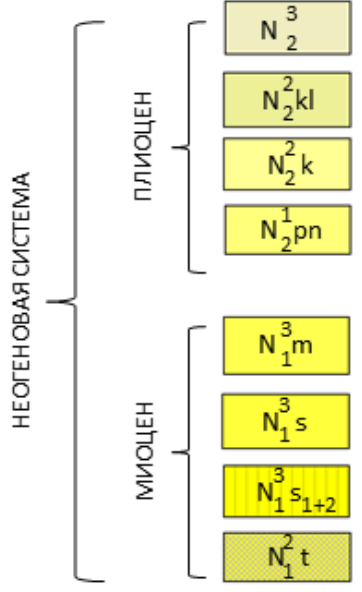

Верхний плиоцен неразделенный. Акчагыльский и апшеронский ярусы. Пески, глины, галечники

Средний плиоцен. Куяльницкий ярус. Глины, пески

Средний плиоцен. Киммерийский ярус. Глины, пески, прослои бүрого железняка

Нижний плиоцен. Понтический ярус. Глины, известняки, песчаники

Верхний миоцен. Мэотический ярус. Глины, конгломераты, известняки

Верхний миоцен. Сармацкий ярус. Глины с прослоями мергелей и известняков

Верхний миоцен. Сармацкий ярус. Глины, пески, прослои бүрого железняка

Средний миоцен. Тортонский ярус. Глины, известняки, песчаники, конгломераты

ПАЛЕОГЕНОВАЯ И ПАЛЕОГЕНОВАЯ И
HЕОГЕНОВАЯ СИСТЕМ

Олигоцен + нижний миоцен. Майкопская серия. Глины с прослоями мергелей, песков и сидеритов

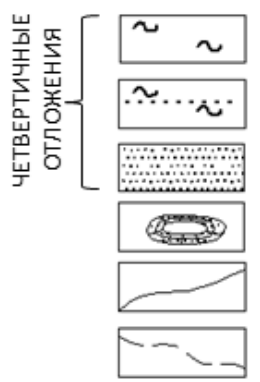

Морские

Дельтово-морские

Континентальные неразделенные

Отложения грязевых вулканов

Границы несогласного залегания отложений

Границы нормального стратиграфического контакта достоверные и предполагаемые

$\sigma / b$

Pис. 2. а) Фрагмент геологической карты района работ. Район исследований обозначен красным прямоугольником; б) условные обозначения к фрагменту геологической карты

Fig. 2. a) fragment of a geological map of the area of work. The study area is indicated by a red rectangle; $b$ ) legend for a fragment of a geological map 


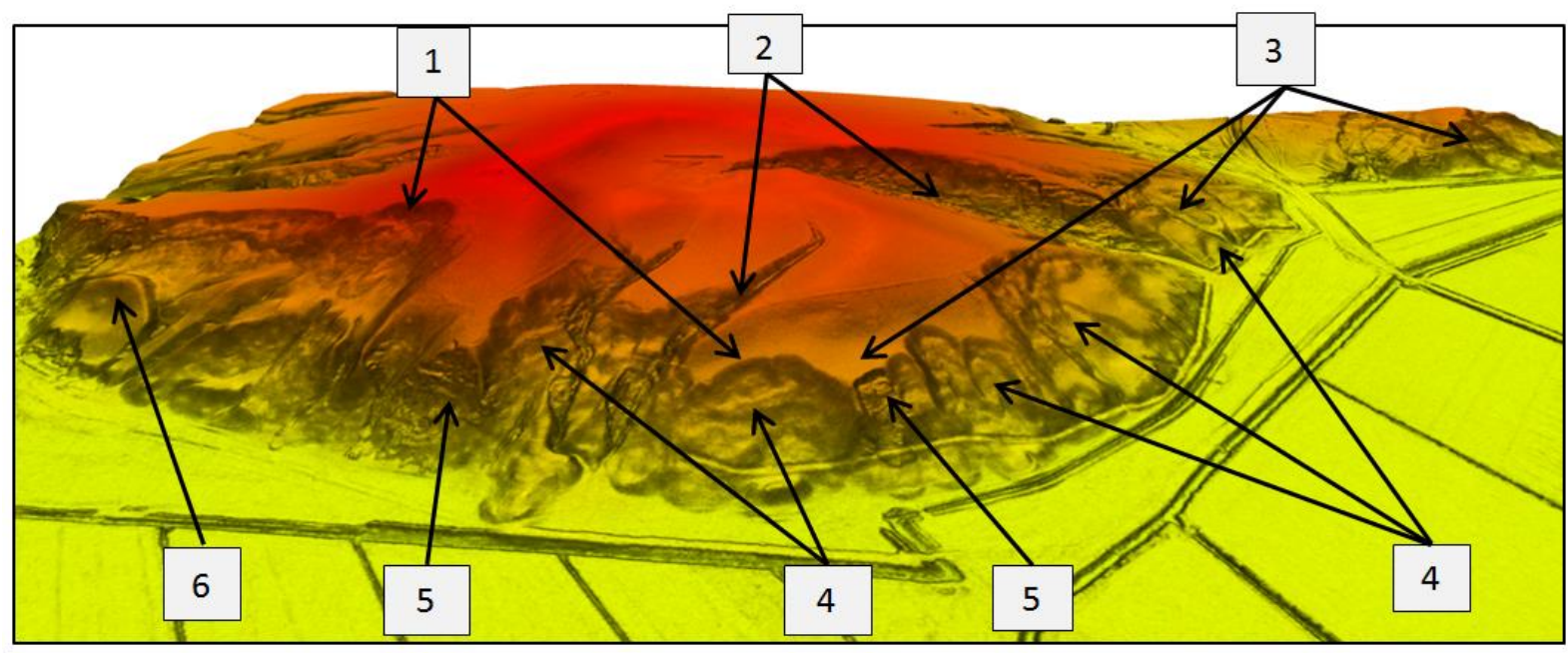

Рис. 3. Оползневый участок: 1) бровка срыва; 2) донная эрозия временного водотока; 3) геоморфологический уступ; 4) оползень вращения; 5) оползень вязкопластического течения; 6) оползень плоского смещения

Fig. 3. Landslide plot: 1) crown; 2) downcutting temporary watercourse; 3) geomorphological ledge; 4) rotational landslide; 5) debris avalanche; 6) translational landslide

Схема современных геологических процессов и условий выполнена на основе данных воздушного лазерного сканирования, в состав которых входит массив точек лазерных отложений, аэрофотоснимок (RGB). Включены картографические материалы ранее выпущенных геологических, гидрогеологических карт и карт четвертичных отложений. На основе собранного материала и полученной модели производилось уточнение границ распространения генетических типов грунтов [7-10].

Таблица 1. Фрагмент таблиць типизированных моделей опасных геологических проиессов

Table 1. Fragment of a table of typed models of hazardous geological processes

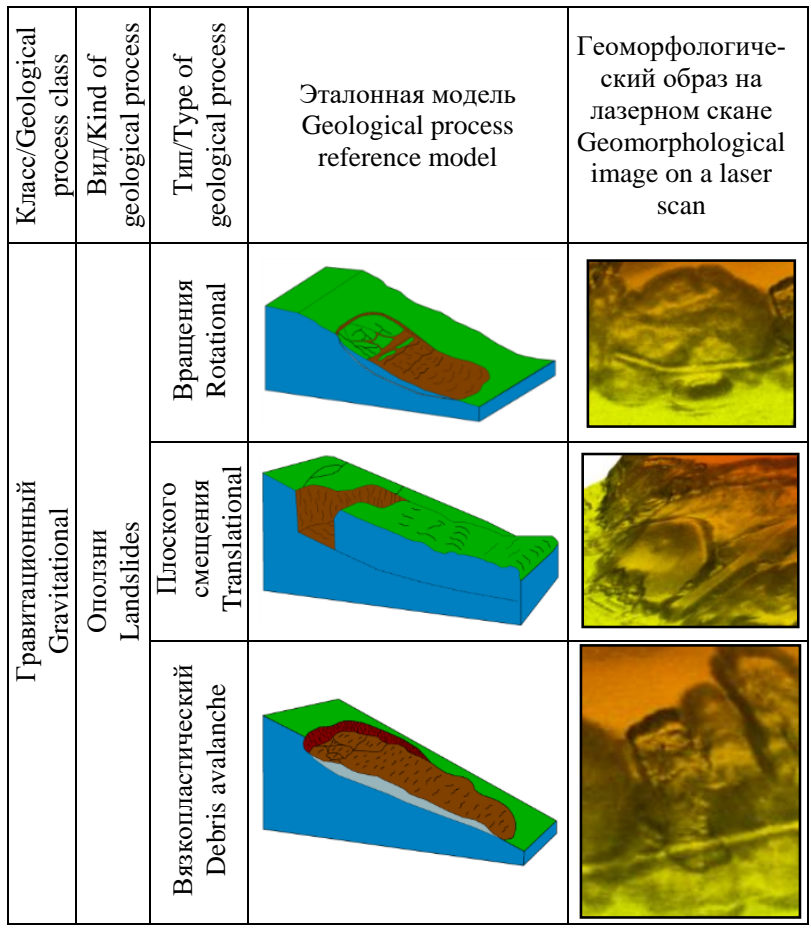

Полученная ЦМР высокой точности (с высокой плотностью точек лазерных отражений), выполненная с высоты 600 м от поверхности земли (количество точек лазерных отражений составило 10 точек на метр квадратный, оборудование компании Leica ALS70-CM было установлено на АН-2), хорошо отображает прямые признаки геологических процессов, их облик и метрические характеристики (рис. 4).

Основные технические характеристики сканера Leica ALS70-CM:

- максимальная высота сканирования 1600 м над земной поверхностью;

- максимальная частота сканирования 500000 импульсов в секунду;

- максимальный поперечный угол сканирования 75 градусов;

- стабилизация по крену при углах крена до 5 градусов на всем диапазоне поперечного угла сканирования;

- количество возвращаемых импульсов неограниченно;

- объем запоминающего устройства 6 ч. непрерывного сканирования;

- рабочие температуры от 0 до 40 градусов Цельсия внутри воздушного судна;

- воздушный лазерный сканер Leica ALS70-CM обеспечивает точность измерений 7-10 см по высоте и 5-15 см в плане в зависимости от высоты сканирования.

Определение типов оползней проводилось путем метода эквивалента при сравнении типизированных моделей оползней (табл. 1).

Выявление опасных геологических процессов (ОГП) на ранних стадиях по данным ВЛС до проведения инженерно-геологических работ дает возможность принятия более качественных предпроектных решений, снижает временные затраты на выявление ОГП, так как обследование проводится точечно для 
фактического подтверждения наличия ОГП. Появляется возможность более качественно расставить гор- ные выработки для изучения природно-геологической среды и обосновать их расположение.

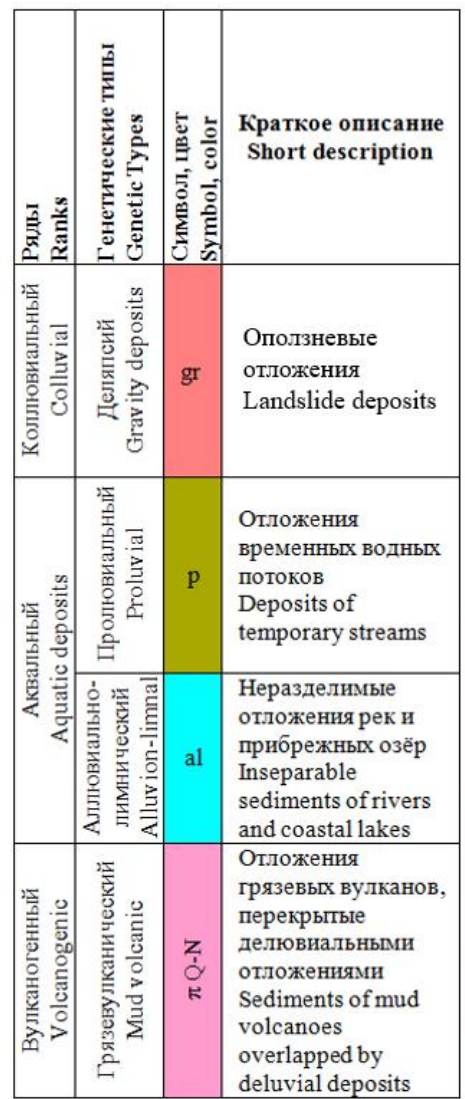

Схема современных геологических процессов и условий. 3D модель рельефа соответствует масштабу топографогеодезической съемке 1:500

Scheme of modern geological processes and conditions. $3 \mathrm{D}$ relief model corresponds to the scale of topographic and geodetic

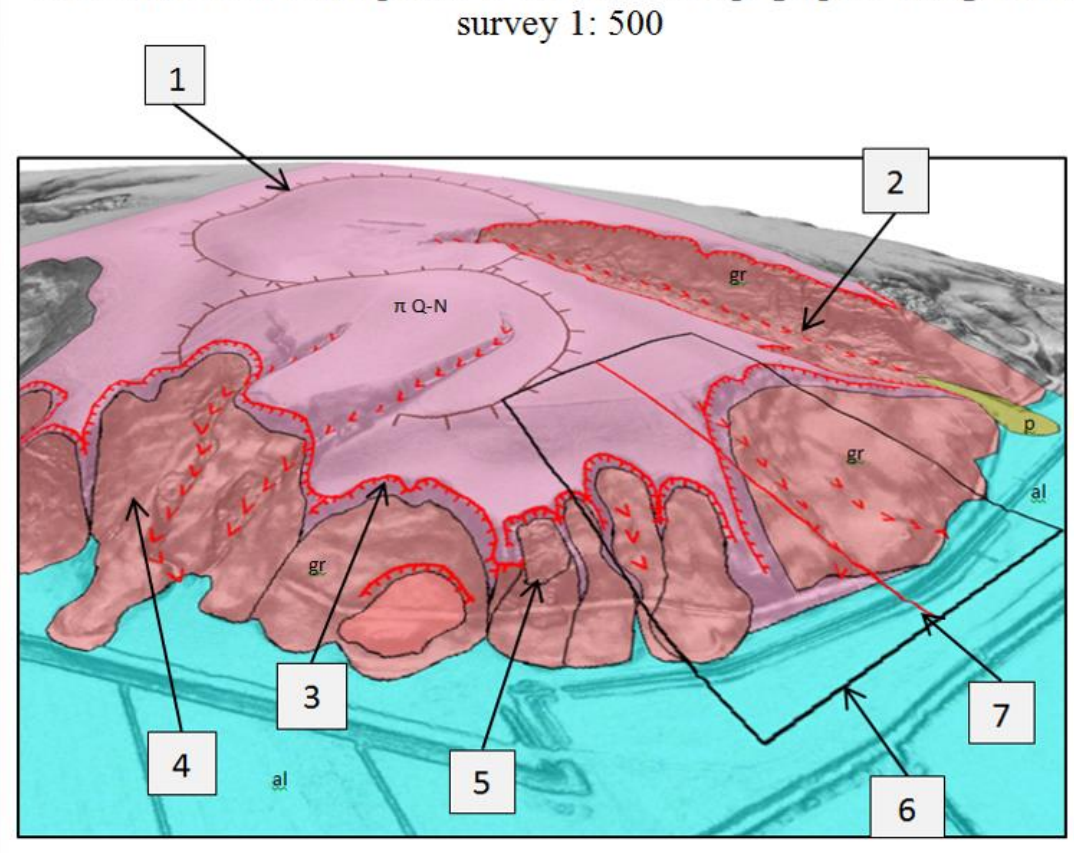

Pис. 4. Схема современных геологических процессов и условий (создана на основе методики дешифрирования материалов воздушного лазерного сканирования): 1) древний кратер грязевого вулкана; 2) донная эрозия временного водотока; 3) бровка срыва; 4) оползень вращения; 5) оползень вязкопластического течения; 6) граница участка исследований; 7) участок трассы проектируемого трубопровода

Fig. 4. Scheme of modern geological processes and conditions (created based on the method of interpretation of LiDAR data): 1) ancient crater of a mud volcano; 2) downcutting temporary watercourse; 3) crown; 4) rotational landslide; 5) debris avalanche; 6) research site boundary; 7) section of the route of the designed pipeline

\section{Полевые исследования на оползневом участке}

При проведении полевых работ были выполнены буровые работы в количестве 44 скв. и комплекс геофизических работ (электроразведка, сейсморазведка по 3 профиля), лабораторные испытания грунтов и др.

По итогам полевых, лабораторных и камеральных работ составлен отчет по инженерно-геологическим изысканиям.

Для демонстрации сопоставления данных дешифрирования материалов ВЛС с данными полевых работ представлена схема фактического материала из отчета по инженерно-геологическим изысканиям (рис. 5).

В целях проведения эксперимента сходимости результатов дистанционного метода дешифрирования материалов ВЛС с полевыми работами производилось сопоставление количественных характеристик оползня, полученных при дешифрировании и полевых работах (периметр, поперечник, площадь и зеркало скольжения по данным дешифрирования и полевых работ) (рис. 4, 5). Карта фактического материала построена по данным воздушного лазерного сканирования, совмещенного с аэрофотосъемкой. При по- строении изолиний с сечением, соответствующим масштабу 1:500, теряется часть информации о микрорельефе, отображающем четкость отражения границ и активность процесса. Для описания качественных и количественных характеристик информативной является цифровая модель рельефа, полученная по данным воздушного лазерного сканирования. Высокая плотность точек лазерных отражений позволяет отобразить мельчайшие подробности геологического процесса.

Границы оползней на карте фактического материала выделялись геологами при натурных исследованиях. Сопоставляя границы, выделенные на цифровой модели рельефа (рис. 4) и на карте фактов (рис. 5), выявлена неточность определения границы оползня геологами, что может повлечь за собой неверные принятия проектных решений.

Для демонстрации сходимости геологического дешифрирования материалов ВЛС с полевыми работами дополнительные профили (для прогнозного определения зеркала скольжения по 3D ЦМР) отстраиваются по профилям полевого исследования $[11,30]$. 


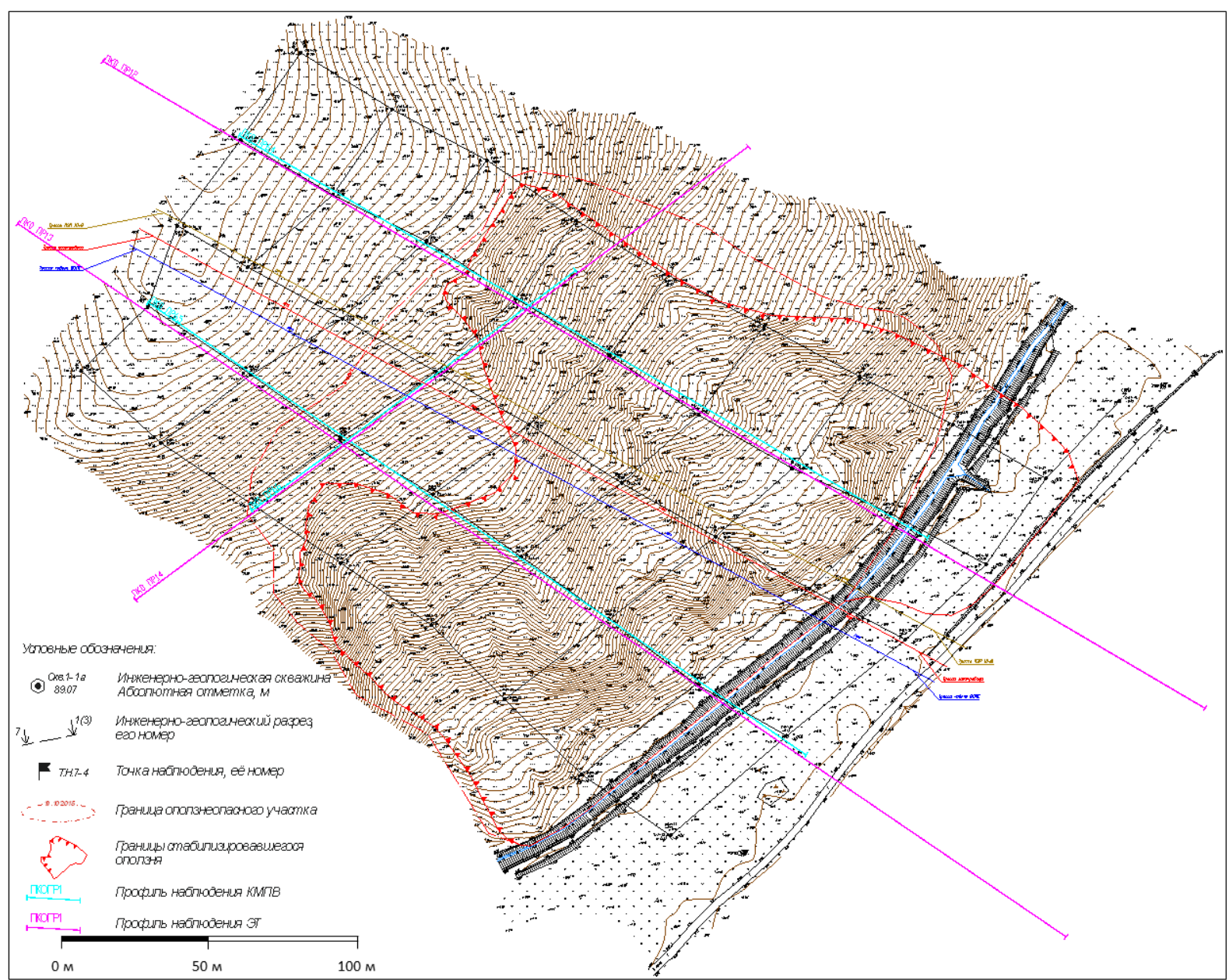

Pис. 5. Карта фактического материала. Масштаб 1:500

Fig. 5. Map of the actual material. Scale 1:500

Оценка глубины предположительного зеркала скольжения на 3D ЦМР производилась до проведения полевых работ по другим профилям.

\section{Сопоставление данных дешифрирования материалов ВЛС и диагностики определения глубины зеркала скольжения и полевых работ}

Определение качественных и количественных характеристик изучаемого оползня на участке является необходимым требованием для инженерных изысканий. Качественные характеристики, определенные по прямым признакам, отображают форму, направление движения во время активизации, подвид оползня (оползень вращения) и его активность. Количественные характеристики определяют размеры, общий уклон образованного тела оползня, размеры головной и подошвенной частей и т. д., также, в случае необходимости, производится описание оползневого тела согласно СП 11-105-97 часть 2 [8].

Внешними факторами определения зеркала скольжения, т. е. криволинейной поверхности, являются: тип оползня (табл. 1), расположение угла наклона бровки срыва, морфологию (текстуру поверхности) видимой части тела оползня, форма подошвы и точка выхода оконечной части $[11,30]$.
Построение плоскостей «вход-выход» на разрезе позволяет выделить предполагаемую границу тела оползня (т. е. объемной геометрической фигуры неопределенной формы) (рис. 6).

Учитывая, что подсчет объёма тела оползня определяется прогнозно, шаг профилирования можно варьировать с учетом формы отображаемой части оползня (т. е. от его формы, отображенной на поверхности). Далее можно приступить к расчету объема геометрической фигуры неопределенной формы.

Рассматривая данную прогнозную оценку тела оползня, необходимо понимать погрешность самого метода определения границы геометрической объемной фигуры неопределенной формы.

Для подтверждения применимости метода дистанционного определения качественных и количественных характеристик проведем сопоставление данных: метода прогнозного определения зеркала скольжения с прямым методом определения границы в точке, совмещенной с косвенными методами определения положения границы между ними (рис. 7-9).

Геофизические работы и интерпретация данных выполнялись специалистами компании ООО «Геопроектстрой» в рамках изучения оползневого участка. 


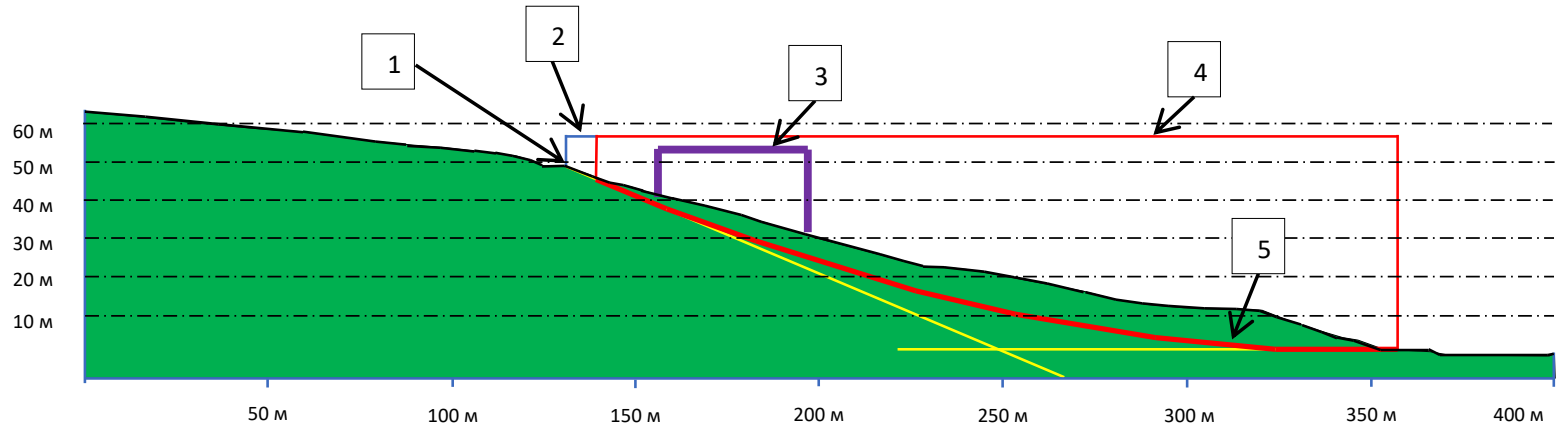

Рис. 6. Профиль по линии 4-4: 1) бровка срыва; 2) проекция главного уступа оползня; 3) проекиия геоморфологического уступа; 4) проекиия тела оползня; 5) предполагаемое зеркало скольжения

Fig. 6. Profile on line 4-4: 1) crown; 2) projection of the main scarp of a landslide; 3) projection of a geomorphological ledge; 4) landslide body projection; 5) alleged surface of rupture

Сравнивая представленные на рис. 7 зеркала скольжения, было установлено, что расчетное зеркало скольжения, произведенное в программном продукте GeoStudio (Slope/W) методом Моргенштерн-Прайса (на рис. 7 обозначено цифрой 6), не совпадает с:

1) зеркалом скольжения оползневого тела при дешифрировании по внешним признакам (по форме бровки срыва, уклону главного уступа, общему уклону склона, форме подошвы оползня и типу оползня по внешним признакам), на рис. 6-9 обозначено цифрой 5

2) зеркалом скольжения по данным геологических и геофизических исследований, на рис. 7 обозначено цифрой 7.

Метод Моргенштерн-Прайса является более точным в том смысле, что он учитывает все три уравнения равновесия: уравнения сил равновесия в горизонтальном и вертикальном направлении, а также уравнение момента равновесия. Коэффициент надежности FS определяется через решение уравнения сил, действующих между блоками, и коэффициента надежности FS [31].

На рис. 7 видна разница определения зеркала скольжения программным продуктом GeoStudio (Slope/W) и методом определения по данным дистанционного метода.

Дальнейшее сопоставление зеркала скольжения, выявленного геофизическими методами, с прогнозным определением зеркала скольжения, отстроенного по данным дистанционного метода, представлено на рис. $8,9$.

На псевдо-разрезе кажущегося сопротивления (рис. 8), построенного с учетом рельефа, выделяются грунты с низким сопротивлением (обозначено тонами синего цвета). Выделенные границы грунтов с низким сопротивлением приурочены к увлажненным грунтам, что частично отображает строение древнего грязевого вулкана. Прослеживается канал разгрузки флюидов, что является одним из важных факторов активизации оползневых процессов. Массив оползневого тела также характеризуется низкими скоростями распространения продольных волн, тем самым подтверждая ранее выделенное положение зеркала скольжения изучаемого оползня по данным дистанционного метода (рис. 8).

Сейсмический разрез склона, характеризующий распределение скоростей продольных (Vp) и поперечных (Vs) волн, их отношения, отображает границы, разделяющие слои вдоль линий повышенных градиентов изменений этих сейсмических свойств (рис. 9). На сейсмическом разрезе значения скоростей увеличиваются с глубиной: Vp - от 200 до 2150 м/c, Vs - от 86 до 312 м/с (рис. 9). Данные диапазоны указывают на неоднородность дисперсных грунтов, слагающих оползневый склон. На сейсмическом разрезе низкие значения скоростей продольных $\mathrm{Vp}$ - от 200 до 1170 м/с и поперечных Vs - от 94 до 217 м/с волн, соответствующие разуплотнённым дисперсным грунтам, выделяются по пикетажу от отметки 150 м до отметки 370 м до глубины 4-10 м.

Значения поперечных Vp и продольных Vs волн тесно связаны с напряженным состоянием грунтового массива. Скорости упругих волн падают с уменьшением сжимающих напряжений и переходом их в растягивающие. На фоне понижения Vs и Vp их отношение $\mathrm{Vs} / \mathrm{Vp}$ возрастает, что характеризует уменьшение значений динамического коэффициента Пуассона. При совмещении выделенной по данным дистанционного метода предполагаемой границы зеркала скольжения с данными сейсмических исследований, происходит прослеживание корреляции этой границы с зоной низких скоростей продольных и поперечных волн, соответствующей зоне разуплотнения дисперсных грунтов.

При сопоставлении выделения границ оползневого тела по данным дистанционного метода и сведениям полевых работ, на рис. 4, 5 видно, что дистанционное выделение оползней, по материалам воздушного лазерного сканирования точнее определяет границы, чем при натурном выделении. В данном случае на неверное установление границ оползневого тела мог повлиять человеческий фактор. Выделение зеркала скольжения при дистанционном методе практически совпало с данными бурения и геофизики (рис. 7-9). 


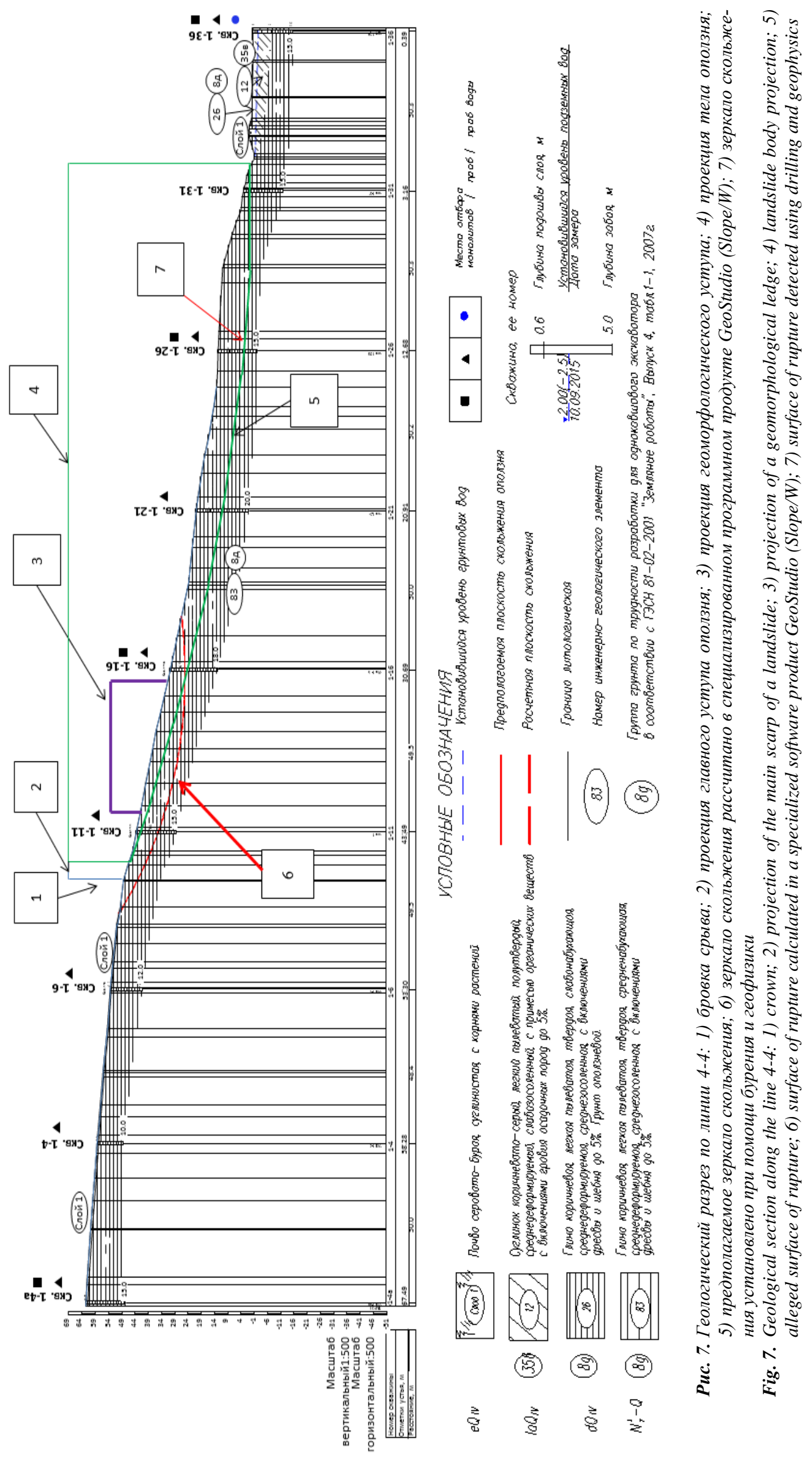




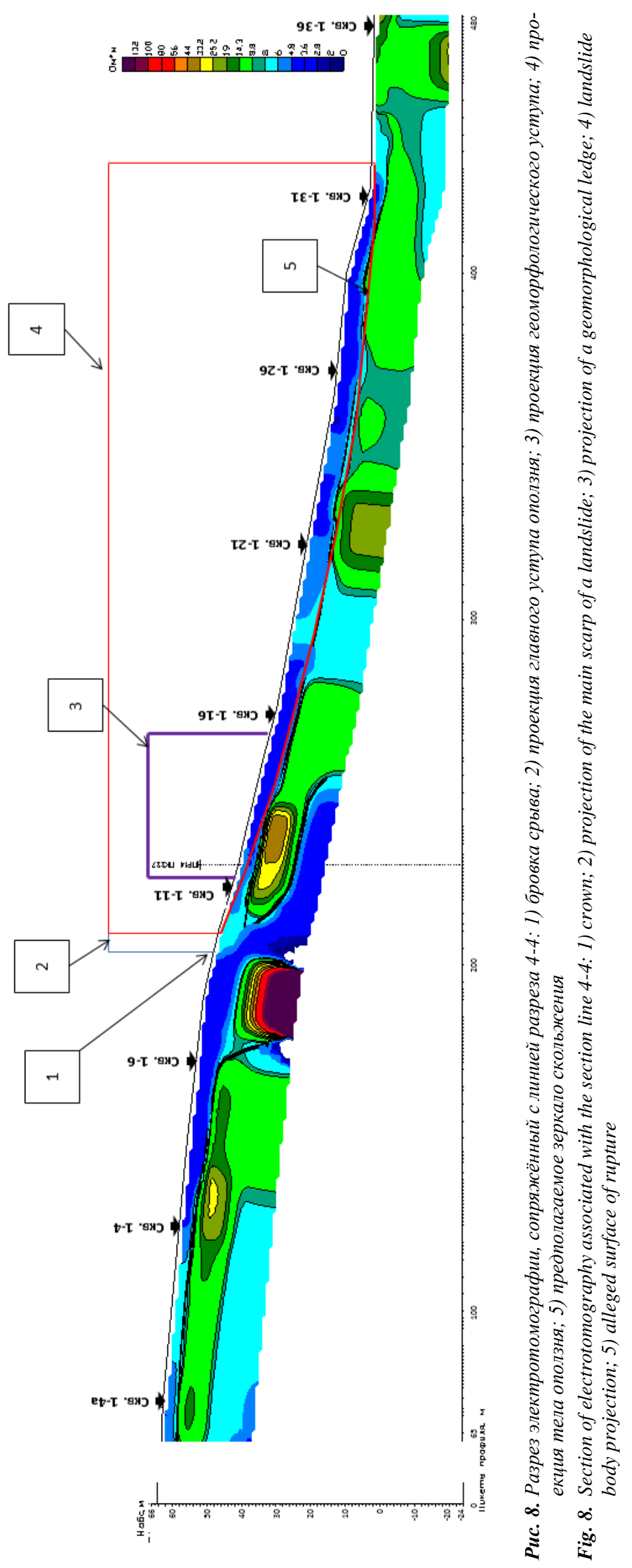




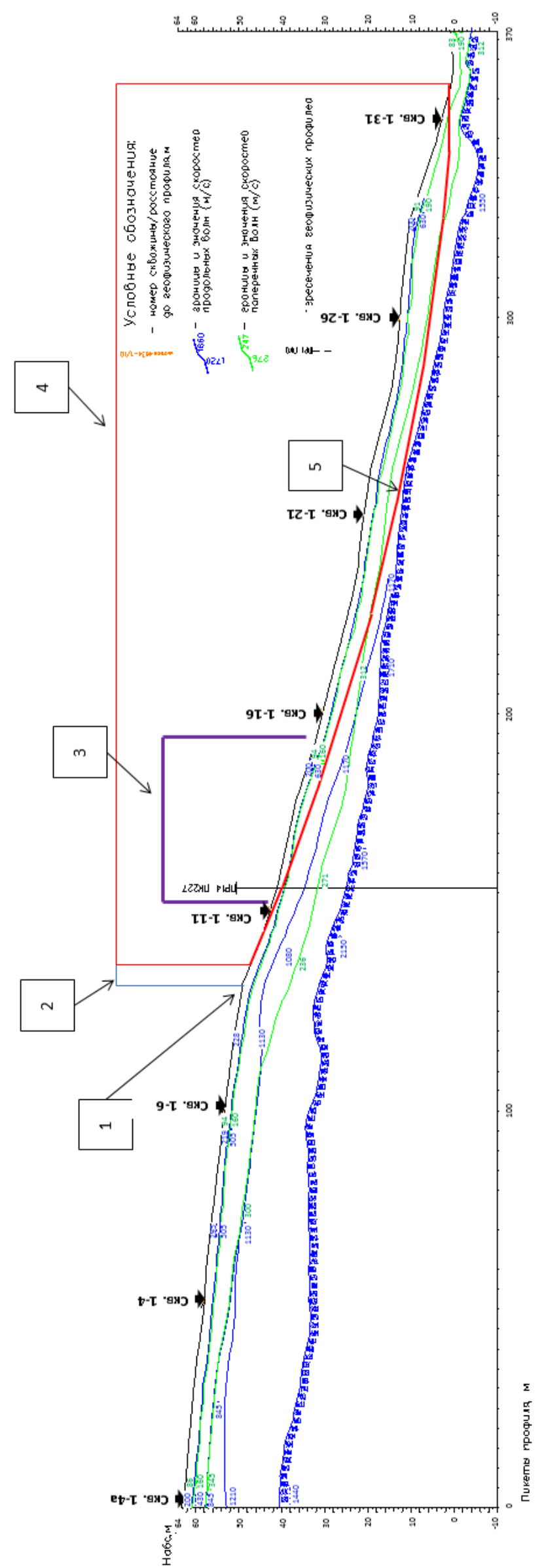

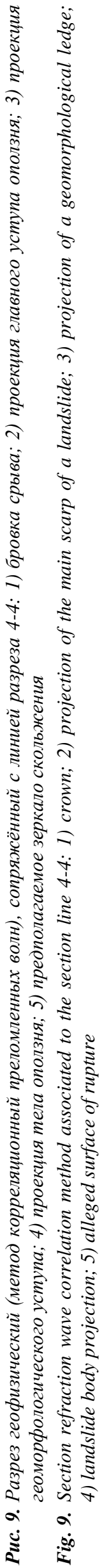




\section{Заключение}

Первоначальная оценка распространения оползней их качественные и количественные характеристики (включая прогнозное определение зеркала скольжения по геометрическим признакам) являются перспективным методом (с учетом применения воздушного лазерного сканирования для получения ЦММ) при изучении местности на стадии принятия проектных решений. Применение данного метода позволяет получить важную инженерно-геологическую инфор-

\section{СПИСОК ЛИТЕРАТУРЫ}

1. Звонкова Т.В. Прикладная геоморфология. - М.: Высшая школа, 1970. -237 с

2. Свод Правил 47.13330.2016 (Свод Правил 47.13330.2012) Инженерные изыскания для строительства. Основные положения. Актуализированная редакция - Свод Норм и Правил 11-02-96. - М.: Стандартинформ, 2017. - 90 с.

3. Свод Правил 11-105-97 часть І. Инженерно-геологические изыскания для строительства. Государственный Комитет Российской Федерации по Жилой и Строительной Политике. - М.: Госстрой России, 1997. -47 c.

4. Баборыкин М.Ю., Жидиляева Е.В., Погосян А.Г. 2015. Выявление опасных геологических процессов при проведении инженерно-геологических изысканий на основе цифровых моделей рельефа // Инженерные Изыскания. - 2015. - № 2. - С. 30-36.

5. Способ дешифрирования экзогенных геологических процессов и геологических условий: пат. Рос. Федерация, № 2655955 , заявл. 16.03.2017; опубл. 30.05.2018. Бюл № 16. -8 с

6. Баборыкин М.Ю. Выстраивание практики и методики взаимодействия проектировщиков и изыскателей при решении задач проектирования на основе данных дешифрирования на объекте Газификация Юго-Западных районов Краснодарского края. - М.: ИЦ «Геомаркетинг», 2015. URL: http://www. geomark.ru/ecwd_event/19-marta-2015-god-i-prakticheskayakonferenciya/attachment/9-baborykin-output/ (дата обращения 12.12.2019)

7. Баборыкин М.Ю. Дистанционное зондирование Земли в инженерной геологии. Создание опережающих инженерногеологических карт // Геоинжиниринг. - 2011. - № 1 (10). C. $38-44$.

8. Свод Правил 11-105-97 часть II. Инженерно-геологические изыскания для строительства. Государственный Комитет Российской Федерации по Жилой и Строительной Политике. - М. Госстрой России, 1997. - 88 с

9. Свод Правил 115.13330.2016. Геофизика опасных природных воздействий. Актуализированная редакция - Свод Норм и Правил 22-01-95. - М.: Министерство Строительства и Жилищно-Коммунального Хозяйства Российской Федерации, 2016. $-36 \mathrm{c}$.

10. Свод Правил 116.13330.2012. Инженерная защита территорий, зданий и сооружений от опасных геологических процессов. Основные положения. Актуализированная редакция - Свод Норм и Правил 22-02-2003. - М.: Министерство Строительства и Жилищно-Коммунального Хозяйства Российской Федерации, 2012. $-59 \mathrm{c}$.

11. Баборыкин М.Ю. Дешифрирование экзогенных геологических процессов по данным воздушного лазерного сканирования. М.: ИЦ «Геомаркетинг», 2016, URL: http://www.geomark.ru/ ecwd_event/21-22-aprelya-2016-goda-i-nauchno-prakticheskayako/attachment/8-baborykin-myu-deshifrirovanie-yekzogen/ (дата обращения 12.12.2019).

12. Ackerman A. Using geologic maps to reduce landslide risk // Factsheet 2018-003, April 2018. April 2018. URL: https://www.americangeosciences.org/sites/default/files/CI_Factsh eet_2018_LandslideGeologicMapping_04202018.pdf (дата обращения 12.12.2019)

13. Baltsavias E.P. Airborne laser scanning: basic relations and formulas. Isprs journal of photogrammetry and remote sensing. 1999. - V. 2-3. - P. 199-214. мацию до проведения полномасштабных полевых работ.

Опыт, накопленный в области применения аэрометодов при изысканиях, показывает их исключительную эффективность по сравнению с традиционными методами сбора информации как в части значительного снижения трудоёмкости и сокращения сроков изысканий, так и в части широты охвата различных видов информации, необходимой для проектирования и планирования дальнейших (детальных) инженерно-геологических работ.

14. Monroy J.D., Khan Sh. Remote sensing techniques make highresolution terrain mapping easier and quicker // Principles of Photogrammetry and LiDAR. - September 1, 2018. URL: https://csengineermag.com/principles-of-photogrammetry-andlidar/ (дата обращения 12.12.2019).

15. Landslide hazard detection from LiDAR data / Ch.K. Toth, O.E. Mora, M.G. Lenzano, D.A. Grejner-Brzezinska. March 2013. URL: https://www.researchgate.net/publication/287398017_Landslide_Haz ard_Detection_From_LiDAR_Data (дата обращения 12.12.2019).

16. Calculation of the rockwall recession rate of a limestone cliff, affected by rockfalls, using cosmogenic chlorine-36. Case study of the Montsec Range (Eastern Pyrenees, Spain) / G. Domènech, J. Corominas, O. Mavrouli, S. Merchel, A. Abellán, S. Pavetich, G. Rugel // Geomorphology. - 2018. - V. 306. - P. 325-335.

17. Cigna F. Observing geohazards from space // Geosciences. 8 February 2018. URL: https://www.mdpi.com/2076-3263/8/2/59 (дата обращения 12.12.2019).

18. Geological outcrop modelling and interpretation using ground based hyperspectral and laser scanning data fusion / J. Howell, T.H. Kurz, S.J. Buckley, D. Schneider. - January 2008. URL: https://www.researchgate.net/publication/228652853_Geological_ outcrop_modelling_and_interpretation_using_ground_based_hype rspectral_and_laser_scanning_data_fusion (дата обращения 12.12.2019).

19. Vertical geology: from remote sensing to 3D geological modelling / F. Humair, B. Matasci, M. Jaboyedoff, A. Abellan, D. Carrea, M.H. Derron, A. Guerin, C. Michoud, P. Nicolet, L. Nguyen, I. Penna, J. Voumard, M. Wyser // Proc. of the first Vertical Geology conference. -Switzerland, 5-7 February 2014. - P. 75-78.

20. Mapping and monitoring geological hazards using optical, LiDAR, and synthetic aperture RADAR image data / K.E. Joyce, S.V. Samsonov, S.R. Levick, J. Engelbrecht, S. Belliss // Nat Hazards. DOI 10.1007/s11069-014-1122-7. URL: https://www.researchgate. net/publication/261070509 (дата обращения 12.12.2019).

21. Mapping and monitoring geological hazards using optical, LiDAR, and synthetic aperture RADAR image data / K.E. Joyce, S.V. Samsonov, Sh.R Levick, J. Engelbrecht // Natural Hazards. September 2014. URL: https://www.researchgate.net/publication/ 261070509_Mapping_and_monitoring_geological_hazards_using optical_LiDAR_and_synthetic_aperture_RADAR_image_data (дата обращения 12.12.2019).

22. Analysis of air-launched ground-penetrating radar techniques to measure the soil surface water content / S. Lambot, L. Weihermüller, J.A. Huisman, C.E. Slob // Water Resources Research. November 2006. URL: https://www.researchgate.net/ publication/46059620_Analysis_of_air-launched_groundpenetrating_radar_techniques_to_measure_the_soil_surface_water _content (дата обращения 12.12.2019).

23. Detecting large-scale landslides using lidar data and aerial photos in the Namasha-Liuoguey Area, Taiwan / Meei-Ling Lin, Te-Wei Chen, Ching-Weei Lin, Dia-Jie Ho, Keng-Ping Cheng, Hsiao-Yuan Yin, Mei-Chen Chen // Remote Sens. - 2014. V. 6. - P. 42-63. DOI: 10.3390/rs6010042.

24. Review of techniques for landslide detection, fast characterization, rapid mapping and long-term monitoring / C. Michoud, A. Abellán, M.H. Derron, M. Jaboyedoff // SafeLand European project. January 2010. - V. 1. - P. 17-19.

25. Landslide research at the British Geological Survey: capture, storage and interpretation on a national and site-specific scale / C.V.L. Pennington, C. Foster, J.E. Chambers, G.O. Jenkins. 
October 2009. - V. 83. - Iss. 5. URL: https://onlinelibrary. wiley.com/doi/abs/10.1111/j.1755-6724.2009.00124.х (дата обращения 12.12.2019)

26. Mahalingam R., Olsen M.J., O'Banion M.S. Evaluation of landslide susceptibility mapping techniques using lidar-derived conditioning factors (Oregon case study). URL: https://www.tandfonline.com/doi/full/10.1080/19475705.2016.117 2520 (дата обращения 12.12.2019).

27. Syed Omar, Zainab Mohamed, Khamarrul Azahari Razak. Landslide susceptibility mapping using LiDAR in Kundasang area: a review // Conference Paper. - March 2018. URL: https://www.researchgate.net/publication/324056936 (дата обращения 12.12.2019).

28. SPH Engineering GPR drone integrated system. URL: https://geomatching.com/uas-for-mapping-and-3d-modelling/gpr-droneintegrated-system (дата обращения 12.12.2019).
29. Assessment of the evolution of a landslide using digital photogrammetry and LiDAR techniques in the Alpujarras Region (Granada, Southeastern Spain) / T. Fernández, J.L. Pérez, C. Colomo, J. Cardenal, J. Delgado, J.A. Palenzuela, C. Irigaray, J. Chacón // Geosciences. - 2017. - V.7 (2). URL: https://www.mdpi.com/2076-3263/7/2/32 (дата обращения 12.12.2019)

30. Баборыкин М.Ю., Кулижников А.М., Еремин Р.А. Комплексное обследование оползней // Автомобильные дороги. - 2018. - № 2 (1035). - С. 106-133.

31. Устойчивость бортов карьеров / С.Г. Оника, Ф.Г. Халявкин, Е.И. Ганцовский, М.В. Семёнова. - Минск: БНТУ, 2016. - 43 с.

Поступила 16.06.2020 2.

\section{Информация об авторах}

Баборыкин М.Ю., ведущий специалист отдела развития инженерных изысканий и проектирования, Специализированный институт по инженерным изысканиям, ООО «НК «Роснефть»- НТЦ». 
UDC 624.131.1:528.7

\title{
CONVERGENCE OF THE RESULTS OF INTERPRETATION REMOTE METHOD WITH FIELD WORK ON A LINEAR OBJECT. ON THE EXAMPLE OF LANDSLIDE PLOT
}

\author{
Maxim Yu. Baborykin, \\ mybaborykin@rnrtc.ru \\ LTD «NC «Rosneft» - Research-and-Technical Centre»,
54, Krasnaya street,_Krasnodar, 350000, Russia.
}

The article discusses the technology of airborne laser scanning used to study the topography, geomorphology and mapping of dangerous geological processes with the description required in the regulatory documents, as well as comparison of the forecast data of the remote method for determining the slip mirror compared with geophysical and geological research methods.

The aim of the study is to obtain positive statistics on using the method of interpretation of hazards geological processes using airborne laser scanning combined with digital aerial photography; to compare the forecast data of the surface of rupture with the classical geological and geophysical studies of the landslide area and, as a result, reveal the reliability of using the interpretation method.

Object: section of the slope of the project pipeline layout. The subject is gravitational geological processes, their form, state and activity. Methods: direct method of interpretation. Since laser scanning of a terrain allows obtaining an array of laser reflection points from the ground surface in the presence of vegetation, the direct method of interpretation allows determining the boundaries and textural features of landslides. Traditional research methods, geodetic survey of the area, drilling of wells, geophysical studies, etc. were used.

Results. Comparison of the remote method and field studies showed a fairly high convergence in identification of landslides (the boundaries of bodies and their appearance). Determination of the proposed surface of rupture landslide in appearance for an assessment in front of the field also shows the convergence of results sufficient for an assessment when choosing competitive areas. World experience gained in the field of application of aerometodes in surveys shows their exceptional efficiency. Thus, the method is effective for making design decisions before field research, and also eliminates the possibility of under-exploration of the territory immediately before the start of field research.

\section{Key words:}

Relief, hazards geological processes, interpretation, study of landslides, engineering-geological mapping, LiDAR, geophysical methods of research, main pipeline.

\section{REFERENCES}

1. Zvonkova T.V. Prikladnaya geomorfologiya [Applied Geomorphology] Moscow, Vysshaya shkola Publ., 1970. 237 p.

2. Svod Pravil 47.13330.2016 (SP 47.13330.2012) Inzhenernyye izyskaniya dlya stroitelstva. Osnovnye polozheniya. Aktualizirovannaya redaktsiya - Svod Norm i Pravil 11-02-96 [Code of Rules 47.13330.2016 (Code of Rules 47.13330.2012). Engineering surveys for construction. The main provisions. Updated edition of the Code of Norms and Rules 11-02-96]. Moscow, Standardinform Publ., 2017. 90 p.

3. Svod Pravil 11-105-97 chast I. Inzhenerno-geologicheskie izyskaniya dlya stroitelstva [Code of rules 11-105-97 part I. Geological engineering surveys for construction]. Moscow, State Committee of the Russian Federation on Residential and Construction Policy, 1997. 47 p.

4. Baborykin M.Yu., Zhidilyaeva E.V., Pogosyan A.G. Identification of hazardous geological processes in engineering surveys based on digital elevation models. Engineering survey, 2015, no. 2, pp. 30-36. In Rus.

5. Baborykin M.Yu. Sposob deshifrirovaniya ekzogennykh geologicheskikh protsessov $i$ geologicheskikh usloviy [The method of interpretation of exogenous geological processes and geological conditions]. Patent RF no. 2655955, 2018.

6. Baborykin M.Yu. Vystraivanie praktiki i metodiki vzaimodeystviya proektirovshchikov $i$ izyskateley pri reshenii zadach proyektirovaniya na osnove dannykh deshifrirovaniya na obyekte Gazifikatsiya Yugo-Zapadnykh rayonov Krasnodarskogo kraya [Building practice and methods of interaction between designers and surveyors in solving design problems based on decryption data at the Gasification Facility in the South-Western regions of the Krasnodar Territory]. Moscow, Geomarketing Publ., March 19 2015. Available at: http://www.geomark.ru/ecwd_event/19-marta2015-god-i-prakticheskaya-konferenciya/attachment/9-baborykinoutput/ (accessed 12 December 2019).

7. Baborykin M.Yu. Remote sensing of the Earth in engineering geology. Creation of engineering-geological maps. Geoengineering, summer, 2011, no. 1 (10), pp. 38-44. In Rus.
8. Svod Pravil 11-105-97 chast II. Inzhenerno-geologicheskie izyskaniya dlya stroitelstva [Code of Rules 11-105-97 Part II. Engineering and geological surveys for construction]. Moscow, State Committee of the Russian Federation on Residential and Construction Policy, 1997. 88 p.

9. Svod Pravil 115.13330.2016. Geofizika opasnykh prirodnykh vozdeystviy. Aktualizirovannaya redaktsiya - Svod Norm i Pravil 22-01-95 [Code of practice 115.13330.2016. Geophysics of natural hazards. Updated edition of the Code of Norms and Rules 22-01-95]. Moscow, Ministry of construction and housing and communal services of the Russian Federation, 2016. 36 p.

10. Svod Pravil 116.13330.2012. Inzhenernaya zashchita territoriy, $z$ daniy $i$ sooruzheniy ot opasnykh geologicheskikh protsessov. Osnovnye polozheniya. Aktualizirovannaya redaktsiya - Svod Norm i Pravil 22-02-2003 [Code of Rules 116.13330.2012. Engineering protection of territories, buildings and structures from dangerous geological processes. The main provisions. Updated edition of the Code of Norms and Rules 22-02-2003]. Moscow, Ministry of construction and housing and communal services of the Russian Federation, 2012. 59 p.

11. Baborykin M.Yu. Deshifrirovanie ekzogennykh geologicheskikh protsessov po dannym vozdushnogo lazernogo skanirovaniya [Interpretation of exogenous geological processes according to LiDAR]. Moscow, Geomarketing Publ. Center, April 21-22, 2016. Available at: http:// www.geomark.ru/ecwd_event/21-22-aprelya2016-goda-i-nauchno-prakticheskaya-ko/attachment/8-baborykinmyu-deshifrirovanie-yekzogen/ (accessed 12 December 2019).

12. Ackerman A. Using geologic maps to reduce landslide risk. Factsheet, 2018-003, April 2018. Available at: https://www.americangeosciences. org/sites/default/files/CI_Factsheet_2018_LandslideGeologicMapping 04202018.pdf (accessed 12 December 2019).

13. Baltsavias E.P. Airborne laser scanning: basic relations and formulas. Isprs journal of photogrammetry and remote sensing, 1999, vol. 2-3, pp. 199-214.

14. Monroy J.D., Khan Sh. Remote sensing techniques make highresolution terrain mapping easier and quicker. Principles of Photogrammetry and LiDAR. September 1, 2018. Available at: 
https://csengineermag.com/principles-of-photogrammetry-andlidar/ (accessed 12 December 2019).

15. Toth Ch.K., Mora O.E., Lenzano M.G., Grejner-Brzezinska D.A. Landslide hazard detection from LiDAR data. March 2013. Available https://www.researchgate.net/publication/287398017 Landslide_Hazard_Detection_From_LiDAR_Data 12 December 2019).

16. Domènech G., Corominas J., Mavrouli O., Merchel S., Abellán A., Pavetich S., Rugel G. Calculation of the rockwall recession rate of a limestone cliff, affected by rockfalls, using cosmogenic chlorine36. Case study of the Montsec Range (Eastern Pyrenees, Spain). Geomorphology, 2018, vol. 306, pp. 325-335.

17. Cigna F. Observing geohazards from space. Geosciences. 8 February 2018. Available at: https://www.mdpi.com/20763263/8/2/59 (accessed 12 December 2019).

18. Howell J., Kurz T.H., Buckley S.J., Schneider D. Geological outcrop modelling and interpretation using ground based hyperspectral and laser scanning data fusion. January 2008. Available

at:

https://www.researchgate.net/publication/228652853_Geological_ outcrop_modelling_and_interpretation_using_ground_based_ hyperspectral_and_laser_scanning_data_fusion (accessed 12 December 2019).

19. Humair F., Matasci B., Jaboyedoff M., Abellan A., Carrea D., Derron M.H., Guerin A., Michoud C., Nicolet P., Nguyen L., Penna I., Voumard J., Wyser M. Vertical Geology: from remote sensing to 3D geological modeling. Proc. of the first Vertical Geology conference. Switzerland, 5-7 February 2014. pp. 75-78.

20. Joyce K.E., Samsonov S.V., Levick S.R., Engelbrecht J., Belliss S. Mapping and monitoring geological hazards using optical, LiDAR, and synthetic aperture RADAR image data. Nat Hazards. DOI 10.1007/s11069-014-1122-7. 18 March 2014. Available at: https://www.researchgate.net/publication/261070509 (accessed 12 December 2019).

21. Joyce K.E., Samsonov S.V., Levick Sh.R., Engelbrecht J. Mapping and monitoring geological hazards using optical, LiDAR, an synthetic aperture RADAR image data. Natural Hazards, September 2014, vol. 73 (2), pp. 1-27. Available at: https://www. researchgate.net/publication/261070509_Mapping_and_monitorin g_geological_hazards_using_optical_LiDAR_and_synthetic_apertur e RADAR image data (accessed 12 December 2019).

22. Lambot S., Weihermüller L., Huisman J.A., Slob E.C. Analysis of air-launched ground-penetrating radar techniques to measure the soil surface water content. Water Resources Research, November 2006. Available at: https://www.researchgate.net/publication/ 46059620_ Analysis_of_air-launched_ground-penetrating_radar techniques_to_measure_the_soil_surface_water_content (accessed 12 December 2019)

23. Meei-Ling Lin, Te-Wei Chen, Ching-Weei Lin, Dia-Jie Ho, KengPing Cheng, Hsiao-Yuan Yin, Mei-Chen Chen. Detecting largescale landslides using lidar data and aerial photos in the NamashaLiuoguey Area, Taiwan. Remote Sens., 2014, vol. 6, pp. 42-63. DOI: $10.3390 / \mathrm{rs} 6010042$

24. Michoud C., Abellán A., Derron M.H., Jaboyedoff M. Review of techniques for landslide detection, fast characterization, rapid mapping and long-term monitoring. SafeLand European project, January 2010, vol. 1, pp. 17-19.

25. Pennington C.V.L., Foster C., Chambers J.E., Jenkins G.O. Landslide research at the British Geological Survey: capture, storage and interpretation on a national and site-specific scale. October 2009, Vol. 83, Iss. 5. Available at: https://onlinelibrary. wiley.com/doi/abs/10.1111/j.1755-6724.2009.00124.x ～(accessed 12 December 2019).

26. Mahalingam R., Olsen M.J., O'Banion M.S. Evaluation of landslide susceptibility mapping techniques using lidar-derived conditioning factors (Oregon case study). Available at: https://www.tandfonline.com/doi/full/10.1080/19475705.2016.117 2520 (accessed 12 December 2019).

27. Syed Omar, Zainab Mohamed, Khamarrul Azahari Razak. Landslide susceptibility mapping using LiDAR in Kundasang area: a review. Conference Paper, March 2018. Available at: https://www.researchgate.net/publication/324056936 (accessed 12 December 2019).

28. SPH Engineering GPR drone integrated system. Available at: https://geo-matching.com/uas-for-mapping-and-3d-modelling/gprdrone-integrated-system (accessed 12 December 2019).

29. Fernández T., Pérez J.L., Colomo C., Cardenal J., Delgado J., Palenzuela J.A., Irigaray C., Chacón J. Assessment of the Evolution of a Landslide Using Digital Photogrammetry and LiDAR Techniques in the Alpujarras Region (Granada, Southeastern Spain). Geosciences, 2017, vol. 7 (2). Available at: https://www. mdpi.com/2076-3263/7/2/32 (accessed 12 December 2019).

30. Baborykin M.Yu., Kulizhnikov A.M., Eremin R.A. A comprehensive survey of landslides. Highways, 2018, no. 2 (1035), pp. 106-133. In Rus.

31. Onika S.G., Khalyavkin F.G., Gantsovsky E.I., Semenova M.V. Ustoychivost bortov karyerov [Stability of the sides of quarries]. Minsk, BNTU Publ., 2016. 43 p.

Received: 16 June 2020.

\section{Information about the authors}

Maxim Yu. Baborykin, chief specialist, Special Institute for Engineering Survey, LTD «NC «Rosneft» - Researchand-Technical Centre». 